\title{
Transfer of cytokines through human fetal membranes
}

\author{
A. S. H. Kent, M. H. F. Sullivan and M. G. Elder \\ Institute of Obstetrics and Gynaecology, Royal Postgraduate Medical School, Hammersmith \\ Hospital, Du Cane Road, London W12 OHS, UK
}

\begin{abstract}
Intact human fetal membranes (amnion, chorion and decidua) were incubated with ${ }^{125}$ I-labelled cytokines added to the fetal or maternal sides of the membrane. The transfer of ${ }^{125}$ I-labelled interleukin-6 (IL-6), ${ }^{125}$ I-labelled tumour necrosis factor $\alpha$ (TNF- $\alpha$ ), ${ }^{125}$ I-labelled interleukin-I $\alpha$ (IL-I $\alpha$ ) and ${ }^{125}$ I-labelled interleukin-1 $\beta$ (IL-1 $\beta$ ) was determined by measurement of radioactivity in a gamma counter and the integrity of the cytokines was assessed by acid precipitation and by radioimmunoassay. IL- $1 \alpha$ and IL-1 $\beta$ were transferred through human fetal membranes in both feto-maternal and materno-fetal directions at similar rates. Only $2-4 \%$ of the cytokine originally added appeared to be intact on the opposing side of the membrane after $24 \mathrm{~h}$ of culture. Transfer of intact TNF- $\alpha(5-7 \%)$ and IL-6 (8-17\%) was greater than that of the IL-1 isomers. Low but variable amounts of the four cytokines tested may be transferred through the human fetal membrane. This finding suggested that concentrations of cytokines in amniotic fluid would not reflect those produced by decidua if the fetal membranes are intact.
\end{abstract}

\section{Introduction}

The biochemical changes accompanying human labour have been investigated and it is apparent that prostaglandin $E_{2}$ $\left(\mathrm{PGE}_{2}\right)$ is involved in cervical ripening (Lorenz et al., 1984), whereas PGF $_{2 \alpha}$ co-ordinates myometrial contractility (Green et al., 1974). Beyond this, the control of human labour remains obscure, such that the factors controlling prostaglandin synthesis at the end of pregnancy have not been identified. However, in the case of intrauterine infection and pre-term labour, substantial progress has been made, showing that increased prostaglandin production may be accompanied by increased concentrations of the cytokine interleukin- $1 \beta$ in the amniotic fluid (Romero et al., 1987, 1989a). A series of studies have shown that the interleukins $-1 \alpha,-1 \beta,-6$ and -8 together with tumour necrosis factor $\alpha$ (TNF- $\alpha$ ) are present at high concentrations in amniotic fluid from pregnant women with obvious evidence of intrauterine infection (Romero et al., 1989a, b, 1990), suggesting that these cytokines are involved in the activation of prostaglandin production from fetal membranes. This contention is supported by a number of studies that have shown that these cytokines stimulate the production of $\mathrm{PGE}_{2}$ from cultured amnion cells (Romero et al., 1989c; Mitchell et al., 1991) and from cultured decidual cells (Casey et al., 1989; Mitchell et al., 1990; Ishihara et al., 1992). A major source of cytokines in amniotic fluid is inflammatory cells present within the infected uterus (Romero et al., 1988), but it is not known whether the decidua is a source of cytokines detected in amniotic fluid in the absence of intrauterine infection and ruptured fetal membranes. In addition, it is thought that the decidua may be the major source of prostaglandins involved in labour (Khan et al., 1991, 1992) and we have found that

Received 22 February 1993.
IL- $1 \alpha$ and IL-I $\beta$ increase the production of prostaglandins by fetal membranes (Kent et al., 1993), the accessibility of amniotic fluid cytokines to the decidua therefore needs to be assessed.

The aim of this study was to examine the transfer of cytokines in both the feto-maternal and materno-fetal directions through cultured human fetal membranes. It is clear from previous studies that fetal membranes actively metabolize prostaglandins (Keirse and Tumbull, 1976; Sullivan et al., 1992); the metabolism of cytokines during transfer through the membranes was therefore also assessed.

\section{Methods}

The culture of intact human fetal membranes has been described in detail by Roseblade et al. (1990). In brief, fetal membranes were obtained from women with term normal pregnancies after delivery by elective Caesarean section. The use of this tissue has been approved (by the Ethical Committee of the Royal Postgraduate Medical School, Hammersmith Hospital and Queen Charlotte's Hospital Special Health Authority) and permission to use the tissue was obtained from the patients. Fetal membrane discs were held over the end of glass cylinders ( $14 \mathrm{~mm}$ diameter) with silicone rubber rings, and incubated with $1.5 \mathrm{ml}$ medium (Medium 199 with $10 \%$ horse serum, $2 \mathrm{mmol}$ glutamine $1^{-1}$ and $1 \%$ penicillinstreptomycin: Gibco, Paisley) on each side. The cells in the membrane are viable by trypan blue (Sigma, Poole) exclusion and diaphorase histochemistry (Roseblade et al, 1990) for at least $120 \mathrm{~h}$ of culture. All experiments described in this paper were terminated at no more than $96 \mathrm{~h}$; the results should therefore not be affected by changes in the cultured membrane. Preliminary studies showed that preincubation of the 
membranes for 24,48 or $72 \mathrm{~h}$ did not affect transfer of the cytokines through the membranes.

${ }^{125}$ I-labelled IL-I $\alpha,{ }^{125}$ I-labelled IL-I $\beta,{ }^{125}$ I-labelled IL- 6 and ${ }^{125}$ I-labelled TNF- $\alpha$ (Amersham International, Amersham) at $100000 \pm 15000$ d.p.m. $\mathrm{ml}^{-1}$ were added to either the fetal side or the maternal side of the cultured fetal membranes for 4-24 h. At the end of the experiments, the medium was taken from both sides of the membrane. The membranes were also removed and split into amnion and chorio-decidual components. Concentrations of ${ }^{125} \mathrm{I}$ in $150 \mu \mathrm{l}$ aliquots of medium and in the split membranes were assessed immediately, and the remainder of the medium was frozen at $-20^{\circ} \mathrm{C}$ (for less than 7 days) until further analysis for integrity of the cytokines. The degradation of the cytokines was assessed by acidifying $150 \mu \mathrm{l}$ aliquots of medium with $10 \%$ trichloroacetic acid and centrifuging at $1500 \mathrm{~g}$ for $10 \mathrm{~min}$ (Habberfield et al., 1986). Small molecular weight fragments remain in solution under these conditions, whereas large polypeptides are precipitated. The extent of cytokine degradation on both sides of the membrane was calculated. Storage of ${ }^{125} \mathrm{I}$-labelled cytokines at $-20^{\circ} \mathrm{C}$ for less than 7 days did not affect the extent of protein precipitation (about $90 \%$ ) in control samples. The data are expressed as percentages to allow comparison between different experiments. Concentrations of immunoreactive cytokines were assessed by radioimmunoassays (Amersham International, Amersham). Data were compared using Student's $t$ test.

\section{Results}

${ }^{125}$ I-labelled IL-1 $\beta$ was added to the fetal side of cultured membranes after $48 \mathrm{~h}$ preincubation, and a detectable transfer of ${ }^{125} \mathrm{I}$ from the fetal to the maternal side of the membranes occurred within $4 \mathrm{~h}$ (Fig. Ia). Radioactivity in the medium on the maternal side of the membrane and in the chorio-decidual tissue increased for up to $24 \mathrm{~h}$ of incubation (Fig. 1a), whereas levels in the amnion remained low. The transfer of radioactivity through the membrane was similar when the ${ }^{125}$ I-labelled IL-1 $\beta$ was added to the maternal side of the membrane (Fig. 1b), which suggested that the transfer of ${ }^{125} \mathrm{I}$-labelled IL-I $\beta$ was equivalent in both directions through the membrane. Similar results were obtained if the preincubation period was $24 \mathrm{~h}$ or $72 \mathrm{~h}$ (results not shown), indicating that the handling of IL-1 $\beta$ did not change during this period of culture.

Analysis of the ${ }^{125}$ I-labelled IL- $1 \beta$ incubated at $37^{\circ} \mathrm{C}$ for $24 \mathrm{~h}$ in culture medium alone (with no tissue present) revealed that $80-90 \%$ of the parent compound was precipitated by the acid treatment, indicating that it was not being broken down. $A$ similar percentage of intact protein was present in the medium from the side of the membranes to which the ${ }^{125}$ I-labelled IL-1 $\beta$ was added (78.6 and $75 \%$, from Table 1$)$. Most of the radioactive compounds detected on the opposing side of the membrane were not acid-precipitable (Table 1), which suggests that most of the cytokine was degraded during transfer through the membrane. A small percentage $(2 \%$ of the original radioactivity) appeared to be intact, indicating that limited transfer of cytokines through the membranes may occur. The integrity of the IL-1 $\beta$ was also assessed by radioimmunoassay of medium from both sides of the membrane. $20 \mathrm{ng} \mathrm{IL-1} \beta \mathrm{ml}^{-1}$ was added to the fetal side of the membrane. After $24 \mathrm{~h}$ of
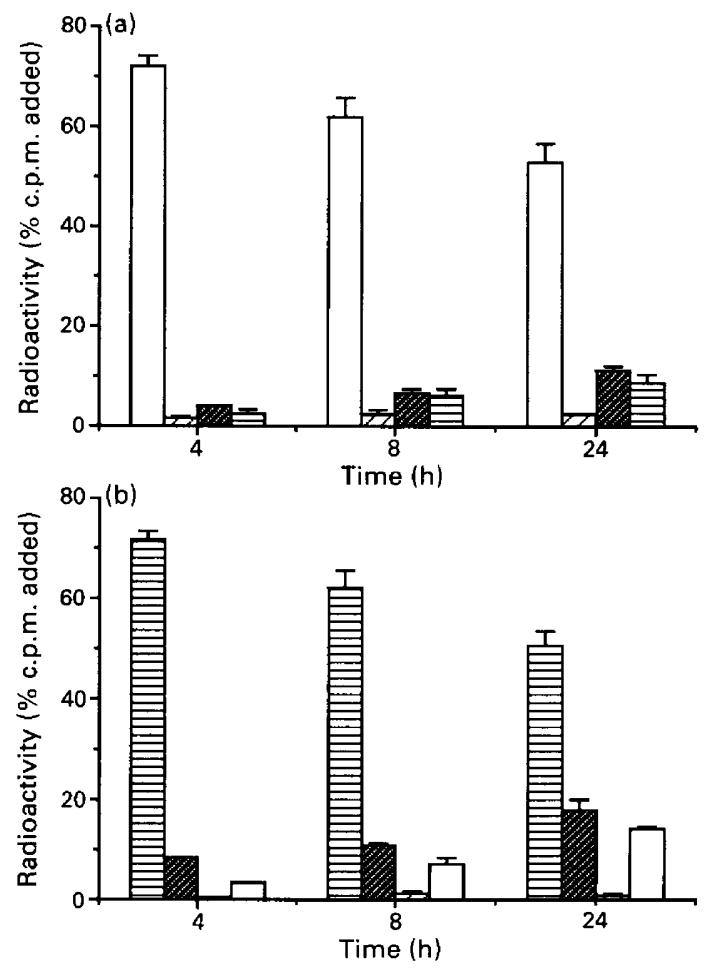

Fig. 1. ${ }^{125}$ I-labelled IL-1 $\beta$ (113 000 d.p.m. $\mathrm{ml}^{-1}$ ) was added to the fetal side (a) of cultured intact fetal membranes after $48 \mathrm{~h}$ of preincubation in medium alone. After the incubation periods shown, the radioactivity (expressed as the percentage of radioactivity added) in the fetal medium $(\square)$ and maternal medium ( $(\boxminus)$ was determined. The membrane disks were split into amnion $(\square)$ and chorio-decidua (囷), and radioactivity measured. In (b) ${ }^{125}$ I-labelled IL-1 $\beta$ (102 000 d.p.m. $\mathrm{ml}^{-1}$ ) was added to the maternal side of the membrane and levels of radioactivity determined in the maternal medium (目), chorio-decidua ( $\square$ ), amnion $(\square)$ and fetal medium ( $\square$ ). Data are means $\pm \operatorname{SEM}(n=3)$.

culture $7.7 \pm 1.1 \mathrm{ng} \mathrm{IL}-1 \beta \mathrm{ml}^{-1}$ remained on the fetal side and only $0.4 \pm 0.1 \mathrm{ng} \mathrm{ml}^{-1}$ was detected on the maternal side $(2.0 \pm 0.5 \%$ transfer). Comparable figures were obtained after the addition of $20 \mathrm{ng}$ IL- $1 \beta \mathrm{ml}^{-1}$ to the maternal side $\left(8.3 \pm 0.3 \mathrm{ng} \mathrm{ml}^{-1}\right.$ on the maternal side and $0.6 \pm 0.2 \mathrm{ng} \mathrm{ml}^{-1}$ on the fetal side), indicating $3 \pm 1 \%$ transfer. Comparison of intact IL-T $\beta$ concentrations after addition to the fetal side showed $50.1 \pm 4.6 \%$ (acid precipitation) and $38.5 \pm 5.5 \%$ (radioimmunoassay), which are not statistically different $(P>0.05)$. Corresponding data after addition to the maternal side were $57.9 \pm 14.3 \%$ and $41.5 \pm 1.5 \%(P>0.05)$, which overall show that about $50 \%$ of the original cytokine remains intact on the side to which it was added after $24 \mathrm{~h}$ of culture.

Essentially similar data were obtained with the other cytokines tested (IL-I $\boldsymbol{\alpha}$, IL- 6 and TNF- $\boldsymbol{\alpha}$ ), in that limited timedependent transfer of intact cytokine occurred (results not shown), and that transfer of cytokines through the membrane was similar in the feto-maternal and materno-fetal directions. The extent of the degradation of the transferred cytokines varied considerably (Table 1). Very little of the IL-1 $\alpha$ was intact, but higher levels of acid-precipitable radioactivity were found when the transfer of TNF- $\alpha$ and IL- 6 were assessed. A minority of the radioactive material that passed though the 
Table 1. Metabolism of cytokines on both sides of human fetal membranes

\begin{tabular}{|c|c|c|c|c|}
\hline \multirow[b]{2}{*}{ Cytokine added } & \multicolumn{2}{|c|}{ Radioactivity not transferred ( $\%$ added) } & \multicolumn{2}{|c|}{ Radioactivity transferred ( $\%$ added) } \\
\hline & Total & Acid-precipitable & Total & Acid-precipitable \\
\hline \multicolumn{5}{|l|}{ To fetal side } \\
\hline IL-I $\beta$ & $63.7 \pm 3.4$ & $50.1 \pm 4.6$ & $7.6 \pm 2.5$ & $2.0 \pm 0.7$ \\
\hline IL-I $\alpha$ & $89.0 \pm 1.1$ & $70.1 \pm 12.0$ & $6.8 \pm 2.9$ & $2.4 \pm 1.2$ \\
\hline IL-6 & $80.4 \pm 1.9$ & $73.4 \pm 2.2$ & $19.1 \pm 2.3$ & $16.3 \pm 2.5$ \\
\hline TNF- $\alpha$ & $73.1 \pm 4.1$ & $55.8 \pm 3.4$ & $20.4 \pm 3.1$ & $6.8 \pm 2.1$ \\
\hline \multicolumn{5}{|l|}{ To maternal side } \\
\hline IL-1 $\beta$ & $77.2 \pm 2.9$ & $57.9 \pm 14.3$ & $11.1 \pm 3.1$ & $3.7 \pm 1.2$ \\
\hline IL-I $\alpha$ & $82.1 \pm 4.6$ & $58.7 \pm 8.2$ & $8.8 \pm 3.6$ & $2.7 \pm 1.5$ \\
\hline IL-6 & $86.6 \pm 2.6$ & $79.4 \pm 5.3$ & $16.2 \pm 1.9$ & $8.6 \pm 1.6$ \\
\hline TNF- $\alpha$ & $73.1 \pm 3.3$ & $55.4 \pm 4.8$ & $20.8 \pm 2.0$ & $5.9 \pm 0.1$ \\
\hline
\end{tabular}

membrane was acid-precipitable when IL-1 $\alpha$, IL-1 $\beta$ and TNF- $\alpha$ were used $(25-35 \%)$, whereas metabolism of IL- 6 seemed to be much less ( $50-85 \%$ acid precipitable). The lower metabolism of IL- 6 was also apparent on the side to which it was added (more than $90 \%$ intact, from Table 1), whereas the other cytokines were $71.5-78.8 \%$ intact (from Table 1 ).

\section{Discussion}

The intact IL-1 $\alpha$, IL-1 $\beta$ and TNF- $\alpha$ remaining in contact with the amnion or the decidua decreased by about $25 \%$ during $24 \mathrm{~h}$ of culture (see above). Spontaneous degradation was about $15 \%$, which suggests that about $10 \%$ of these cytokines was metabolized by amnion and decidua. In contrast, $65-75 \%$ of the IL-I $\alpha$, IL-I $\beta$ or TNF- $\alpha$ passing through the membrane was metabolized, indicating that the major breakdown of the cytokines occurred during transfer through the membranes. To cross the membrane, the cytokines must pass through the chorion; we therefore suggest that most of the metabolism occurs in this tissue. Similar data have been reported for $\mathrm{PGE}_{2}$ (Roseblade et al., 1991).

The transfer and metabolism of IL- 6 differed from that of the other three cytokines tested. In particular, relatively high amounts of intact IL- 6 passed through the membrane. We attribute this high transfer to low metabolism of IL-6 within the membrane on the following basis: metabolism of the other cytokines during transfer was $65-75 \%(25-35 \%$ intact); applying these figures to the total IL- 6 transferred (16.2-19.1\%) would suggest a maximum transfer of intact IL- 6 of $6.7 \%$ $(19.1 \% \times 0.35)$ and a minimum transfer of $4.1 \%(16.2 \% \times 0.25)$. These results resemble the actual data obtained for the other cytokines. It is clear that fetal membranes may produce large amounts of IL-6 (Romero et al., 1990), and this may act as a block on metabolism of IL- 6 added to either side of the membrane, but further studies are needed to assess this. The cytokine metabolites were not identified, although the loss of immunoreactivity and the solubility of the radioactive compounds in the presence of $10 \%$ trichloroacetic acid indicates that small peptides were being produced.

The transfer of intact IL- $1 \alpha$ and IL-1 $\beta$ was similar to the transfer of intact $\mathrm{PGE}_{2}$ through fetal membranes (Bennett et al., 1990; McCoshen et al., 1990; Roseblade et al., 1990), in the range of $1-4 \%$. These results suggest that these bioactive compounds are likely to be synthesized within, or very close to, the tissues on which they act. Thus the prostaglandins, which act on the myometrium, and cytokines, which act on the decidua, may be produced by the decidual-myometrial region of the uterus. This contention supports earlier suggestions that decidual activation has a major role in preterm labour associated with infection (Romero et al., 1988), and is consistent with a recent report implicating decidual activation in term labour (Khan et al., 1992). The enzymes responsible for the metabolism of the cytokines observed in the study have not been identified, although it seems likely that nonspecific proteases are most likely to be involved, as three of the four cytokines were degraded to the same extent. The internalization and degradation of IL-1 $\beta$ after binding to the cell-surface receptor depends on the type of receptor present (Horuk, 1991), in that cells with the $80 \mathrm{kDa}$ (type I) receptor internalized, but did not degrade, the cytokine to acid soluble products, whereas cells with the type II receptor internalized $15 \%$ of the bound cytokine, of which $40 \%$ was released as acid-soluble products (Horuk, 1991). It is not known whether decidual cells possess only one or both receptors; further studies will therefore be needed to determine the contributions of decidua and chorion to overall cytokine metabolism.

Cytokines have been implicated in normal labour (Ishihara et al., 1992; Khan et al., 1992), but concentrations of the interleukins in amniotic fluid do not increase greatly during this 
process (Romero et al., 1989a, b, 1990). We suggest that when the fetal membrane is intact, decidual cytokines have only limited access to the amniotic fluid, and the changes cannot be detected by the techniques currently used. Only after membrane rupture would there be ready transfer of cytokines between the amniotic fluid and the decidua. This may also indicate that in women with intrauterine infection either the amnion or fetus produces cytokines, or the fetal membranes are damaged or ruptured so that decidual cytokines may gain access to the amniotic fluid, as it has been clearly demonstrated that in such cases there are very high concentrations of cytokines in the amniotic fluid (Romero ef al., 1989a, b, 1990). We have recently found that IL-I $\alpha$ and IL-1 $\beta$ activate prostaglandin production by human fetal membranes (Kent et al., 1993), and that there seems to be some transfer of bioactive cytokines, between $1-4 \%$, which supports the direct measurements in this study and implies that cytokines will be active in the tissues in which they are produced.

The authors thank Action Research for a Perinatal Research Fellowship (A. S. H. Kent).

\section{References}

Bennett PR, Chamberlain GV, Patel L, Elder MG and Myatt L (1990) Mechanisms of parturition: the transfer of prostaglandin $\mathrm{E}_{2}$ and 5-hydroxyeicosatetraenoic acid across fetal membranes American journal of Obstetrics and Gynecology 162 683-687

Casey ML, Cox SM, Beutler B, Milewich L and MacDonald PC (1989) Cachetin/ tumor necrosis factor- $\alpha$ formation in human decidua. Journal of Clinical Investigation 83 430-436

Green K, Bygdeman M, Toppozada M and Wiqvist N (1974) The role of prostaglandin $\mathrm{F}_{2 \alpha}$ in human parturition American journal of Obstetrics and Gynecology 120 25-31

Habberfield AD, Dix CJ and Cooke BA (1986) Evidence for the rapid internalisation and recycling of lutropin receptors in rat testis Leydig cells Biochemical Journal 233 369-376

Horuk R (1991) Differences in the internalization and intracellular processing of interleukin-1 associated with the two forms of interleukin-1 receptor found in B-cells and T-cells Biochemical Journal 273 79-83

Ishihara O, Khan H, Sullivan MHF and Elder MG (1992) Interleukin-I $\beta$ stimulates decidual stromal cell cyclo-oxygenase enzyme and prostaglandin production Prostaglandins 44 43-52

Keirse MJNC and Turnbull AC (1976) The fetal membranes as a possible source of amniotic fluid prostaglandins British Joumal of Obstetrics and Gynaecology 83 146-151
Kent ASH, Sun M-Y, Sullivan MHF and Elder MG (1993) Effects of interleukins $1 \alpha$ and $1 \beta$ on prostaglandin production by cultured human fetal membranes Prostaglandins 46 51-59

Khan H, Sullivan MHF, Helmig R, Roseblade CK, Uldbjerg N and Elder MG (1991) Quantitative production of prostaglandin $E_{2}$ and its metabolites by human fetal membranes British Journal of Obstetrics and Gynaecology 98 $712-715$

Khan H, Ishihara O, Sullivan MHF and Elder MG (1992) Changes in decidual stromal cell function associated with labour British joumal of Obstetrics and Gynaecology 99 10-12

Lorenz RP, Botti JJ, Chez RA and Bennett N (1984) Variations of biologic activity of low-dose prostaglandin E2 on cervical ripening Obstetrics and Gynecology 64 123-127

McCoshen JA, Hoffman DR, Kredentser JV, Araneda C and Johnston JM (1990) The role of fetal membranes in regulating production, transport, and metabolism of prostaglandin $\mathrm{E}_{2}$ during labor American Journal of Obstetrics and Gynecology 163 1632-1640

Mitchell MD, Edwin S and Romero RJ (1990) Prostaglandin synthesis by human decidual cells: effects of inflammatory mediators Prostaglandins Leukotrienes and Essential Fatty Acids 41 35-39

Mitchell MD, Dudley DJ, Edwin SS and Schiller SL (1991) Interleukin-6 stimulates prostaglandin production by human amnion and decidual cells European Journal of Pharmacology 192 189-191

Romero R, Emamian M, Wan M, Quintero R, Hobbins JC and Mitchell MD (1987) Prostaglandin concentrations in amniotic fluid of women with intra-amniotic infection and preterm labor American Journal of Obstetrics and Gynecology 157 1461-1467

Romero R, Mazor M, Wu YK, Sirtori M, Oyarzun E, Mitchell MD and Hobbins JC (1988) Infection in the pathogenesis of preterm labor Seminars in Perinatology $12262-279$

Romero R, Brody DT, Oyarzun E, Mazor M, Wu YK, Hobbins JC and Durum SK (1989a) Infection and labor III. Interleukin-1: a signal for the onset of parturition American Journal of Obstetrics and Gynecology 160 1117-1123

Romero R, Manogue KR, Mitchell MD, Wu YK, Oyarzun E, Hobbins JC and Cerami A (1989b) Infection and labor IV. Cachetin - tumor necrosis factor in the amniotic fluid of women with intraamniotic infection and preterm labor American Joumal of Obstetrics and Gynecology 161 336-341

Romero R, Durum S, Dinarello CA, Oyarzun E, Hobbins JC and Mitchell MD (1989c) Interleukin-I stimulates prostaglandin biosynthesis by human amnion Prostaglandins 37 13-19

Romero R, Avila C, Santhanam U and Sehgal PB (1990) Amniotic fluid interleukin 6 in preterm labor. Association with infection Journal of Clinical Investigation 85 1392-1400

Roseblade CK, Sullivan MHF, Khan H, Lumb MR and Elder MG (1990) Limited transfer of prostaglandin $\mathrm{E}_{2}$ across the fetal membranes before and after labour Acta Obstetrica et Gynecologica Scandinavica 69 399-403

Roseblade CK, Sullivan MHF and Elder MG (1991) Metabolism of prostaglandin $\mathrm{E}_{2}$ on the fetal and maternal side of intact fetal membrane Acta Obstetrica et Gynecologica Scandinavica 70 425-427

Sullivan MHF, Roseblade CK, Rendall NB, Taylor GW and Elder MG (1992) Metabolism of prostaglandins $E_{2}$ and $F_{2 \alpha}$ by human fetal membrane Biochimica et Biophysica Acta 1123 342-346 